\title{
Analysis of the variables: Commodity price and discount rate on long-term open pit mine planning
}

\author{
Fontes MP $1,{ }^{*}$, Koppe JC ${ }^{2}$ and Silva Neto JA ${ }^{3}$ \\ ${ }^{1}$ Federal University of Rio Grande do Sul - UFRGS, Federal Centre for Technology Education of Minas Gerais - CEFET-MG, \\ Araxá, Brazil. \\ 2 Federal University of Rio Grande do Sul - UFRGS, Porto Alegre, Brazil. \\ ${ }^{3}$ Federal Centre for Technology Education of Minas Gerais - CEFET-MG, Araxá, Brazil.
}

Global Journal of Engineering and Technology Advances, 2021, 06(02), 142-150

Publication history: Received on 18 January 2021; revised on 20 February 2021; accepted on 22 February 2021

Article DOI: https://doi.org/10.30574/gjeta.2021.6.2.0025

\begin{abstract}
Long-term open pit mine planning is a complex process which deals with numerous uncertainties, whether they are economical (commodity price, operational costs, production schedule, discount rate, inflation, among others); geological (grade distribution, density, hardness, etc); or physical constraints (property limits, environmental issues, legislation, etc). In this context, this paper aims to evaluate the effects of the variation of two important variables: commodity price and discount rate, with regard to the economic criterion, represented by the Net Present Value (NPV) of the mining business. Starting from a baseline value of US\$ 80/t, the commodity (phosphate rock was used as a case study) price was varied within a $50 \%$ range, above and below the baseline value, obtained from historic values from the last 5 years. The discount rate values adopted in the analyses were $6 \%, 8 \%, 10 \%, 12 \%, 14 \%, 16 \%, 18 \%$ and $20 \%$. The results showed increases in the market price yielded higher NPV and life of mine values. On the other hand, it was noted that increases in the discount rate can significantly alter the NPV, materially reducing the value of the mining undertaking. It is also worth noting that, in contrast to more robust approaches such as Real Options Theory (ROT), traditional Discounted Cash Flow (DCF) methods, such as NPV, assume variables, such as commodity price, to be fixed, which could either lead to the undervaluation or overvaluation of a project.
\end{abstract}

Keywords: Open pit Mine Planning; Commodity Price; Discount Rate; Net Present Value

\section{Introduction}

Mining activities have, for thousands of years, constantly contributed to the development of society as a whole, with the high living standards of modern day's society being now completely dependent upon the production of mineral goods. Nevertheless, the success of a mining business from a production standpoint is not always followed by its success from an economic perspective. The mining industry has contributed to 4.3\% of Brazil's Gross Domestic Product (GDP) in 2017 , peaking at a value of US\$21.6 billion, of which $62 \%$ came from iron ore concentrate [1].

Mining projects are complex businesses which constantly demand risk evaluation [2 - 4]. That is because the value of the project can be altered by numerous variables, whether they are economic (commodity price, operational costs, production schedule, discount rate, inflation, among others); geological (grade distribution, density, hardness, etc); or physical constraints (property limits, environmental issues, legislation, etc). Thus, the evaluation and estimation of a mining project's value, not to mention the risks of future losses (or opportunities), could certainly lead to unsatisfactory

\footnotetext{
${ }^{*}$ Corresponding author: Fontes MP

Federal University of Rio Grande do Sul - UFRGS, Federal Centre for Technology Education of Minas Gerais - CEFET-MG, Araxá, Brazil..
} 
results. Therefore, managers and stakeholders have no other option but to make decisions based on inconsistent information.

Over the years, many studies have been developed in order to assess uncertainties in mining projects. For instance, one of the researchers who recognised the importance of considering uncertainties in mineral projects related to commodity price was Tourinho [5]. With regards to production cost uncertainties, one of the early publications were from Palm [6] and for geological and grade uncertainties, there were mentions from Dowd [7], Dimitrakopoulos and Godoy [8].

As stated by [9 - 11], investments in the mining business are always subject to high volatility due to constant changes in the industry. Future fluctuations in the commodity price, for instance, can potentially alter the profitability expectations of the mining undertaking during its lifespan, which in turn calls for new calculations and optimisations to be carried out in order to adjust to the new economic conditions.

In an open pit mine, the main goal of long-term production planning is to maximise the NPV of the mining business by finding an optimal extraction sequence, which is subject to financial, technical, and environmental constraints [12 - 16]. Carefully considering the risks associated with these constraints and with economic, physical, and environmental parameters is, therefore, substantially significant to the success of the mine scheduling process.

Consequently, it can be said that the success of a mining project lies in both the carrying out of an adequate strategic mine planning process and in the ability to quickly adapt the mining strategy to constantly altering market conditions. That is because, in the mining industry, large investments are made in the prospecting, exploration, development and exploitation phases. Therefore, devising a well-thought-out strategic open pit mine plan is vital not only to ensure the return on investment, but also to minimise costs and maximise the profitability and longevity of the mining business during its lifetime.

Another issue that should not be neglected is the fact that a certain high-cost asset must be subjected to higher risk adjustments than one of much lower cost [17]. This adjustment can be done through a discount rate which is used in the NPV calculations and can usually be determined by assessing the Weighted Average Cost of Capital (WACC) or by Capital Asset Pricing Model (CAPM), as described by [18]. It is commonly accepted in the mining industry that the cash flow of mining undertakings of high-cost assets is more sensitive to, for example, changes in the commodity price, and therefore should employ higher discount rates in their NPV calculations.

In defining the appropriate discount rate, many mining businesses end up employing a static value of $15 \%$ in their DCF calculations [19]. Other authors, like [20], state that because it is difficult to correctly define the discount rate, some companies, as well as the government, resort to rather simplistic approaches, such as using " $20 \%$ for the exploration phase, and $10 \%$ thereafter". In other cases, companies simplify this process even more by choosing a single discount rate value and using it throughout all the stages of the mine life. In Brazil, commonly used values for the discount rate tend to vary between $12 \%$ and $18 \%$. Accurately defining the discount rate of a mining business is crucial since cashflow calculations can be significantly sensitive to the rates chosen.

Many companies also employ sensitivity analyses in the long-term planning process in order to evaluate the impact of the most important input variables on the profitability of the project. In this process, one or more of the input variables is varied, and its effects on the profitability, for example, are observed. Nevertheless, this methodology has one significant downside: In this type of analysis, it is assumed that all other things remain unchanged, which is especially untrue for mining business, which must constantly adjust due to changes in the external environment.

In light of the aforementioned, the main objective of this paper is to demonstrate the effects of the uncertainties associated with commodity price (using phosphate rock as a case study) and the discount rate on the long-term open pit mine planning process. Firstly, a sensitivity analysis will be carried out where only the phosphate rock price will be varied within a certain range. In this scenario, the effects on the optimal final pit limits will be assessed calculating, for each price scenario, the values of ore and waste tonnage, stripping ratio, average P205 grade of the final pit and the lifespan of the mining business. Secondly, a joint analysis will be employed varying both, the price, and the discount rate. In this scenario, the profitability of the mining enterprise will be evaluated in the form of the total NPV of all the yearly cash flows obtained over the life of the mine. 


\section{Methodology}

The methodology employed in this research follows the basic steps of the strategic long-term planning process of an open pit mine. It starts with a three-dimensional representation of the mineral deposit in the form of a block model. In the next stage, the block model is then evaluated by a profit function originating an economic model, where each block now has a profit value, whether they are positive, negative or zero. Based on this economic model, an optimisation algorithm, such as the [21], is applied in order to obtain the final pit limits which maximise the profits of the mining business. Then, the final pit is divided into large portions called pushbacks. Lastly, the pushbacks are then scheduled for yearly production and based on the expected yearly cash flows, it is possible to obtain a preliminary indication of the NPV of the mining business.

In this paper, this methodology will be repeated many times in order to evaluate the impact of the variables studied for each scenario assessed. Figure 1 schematically illustrates all the steps of the methodology used in this study.

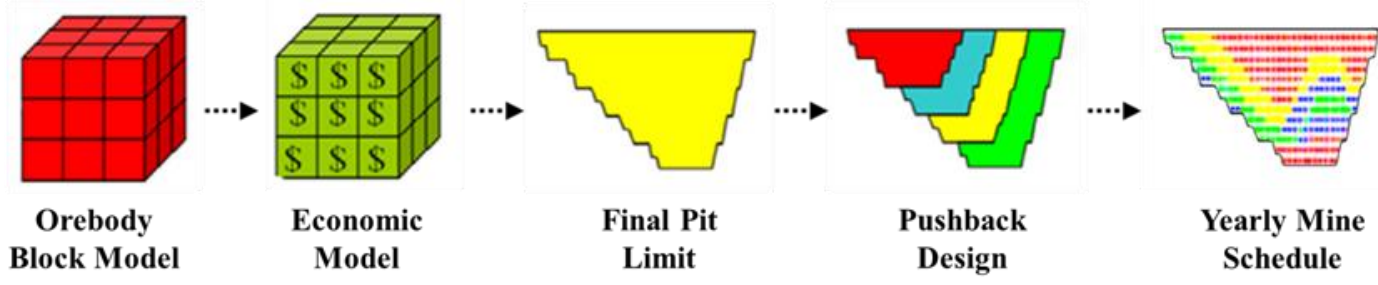

Figure 1 Open pit mine planning process methodology.

For the purposes of this work, a block model and the topographic data of a phosphate rock deposit will be used. The mineral deposit is located in Araxá, Brazil. The baseline value for the phosphate rock market price adopted was US\$ $80 / t$, which is similar to the actual market price at the time of writing this paper. Based on historical data from the last five years, it was possible to define the range at which the price would be varied to generate the different price scenarios. From 2013 to 2018, phosphate rock price declined roughly 55\%, going from US\$179/t in January 2013, to US\$ 81/t in January 2018. Figure 2 shows the curve that represents the variation of phosphate rock price over the chosen time period.

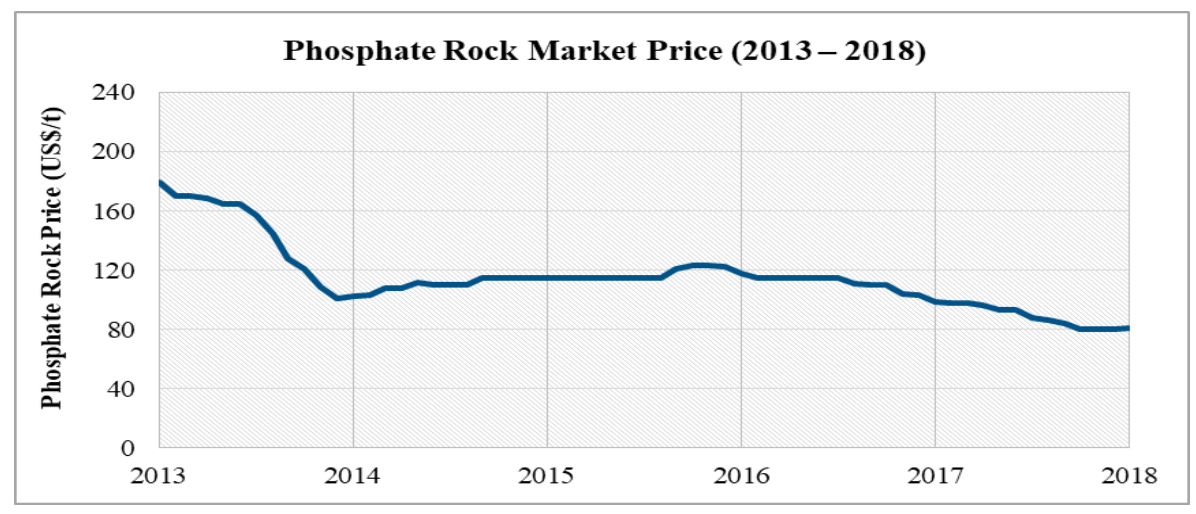

Figure 2 Phosphate rock Market price history from the last 5 years. Source: Adapted from Global Economic Monitoring (GEM) Commodities, World Bank Group.

Based upon the variation displayed by the curve in Figure 2, a sensitivity analysis with a range of $50 \%$, above and below the baseline value of US\$ $80 / t$, was employed. Through $25 \%$ increments, the price was varied within the established range, originating five different price scenarios: US\$ 40/t; US\$60/t; US\$ 80/t; US\$100/t and US\$120/t. With regard to the discount rate, the values chosen were from $6 \%$ to $20 \%$, with $2 \%$ increments, originating the following discount rate scenarios: $6 \% ; 8 \% ; 10 \% ; 12 \% ; 14 \% ; 16 \% ; 18 \%$ and $20 \%$. The authors hoped that, with such amplitude, most mineral commodities would be encompassed, including phosphate rock. The tests consisted of evaluating, for each price scenario, the effects of changing the discount rate in the economic criterion, represented by the DCF calculations, ultimately observing how the NPV of the mining business would change in each scenario studied. Figure 3 shows a flowchart of the methodology adopted in this paper. 


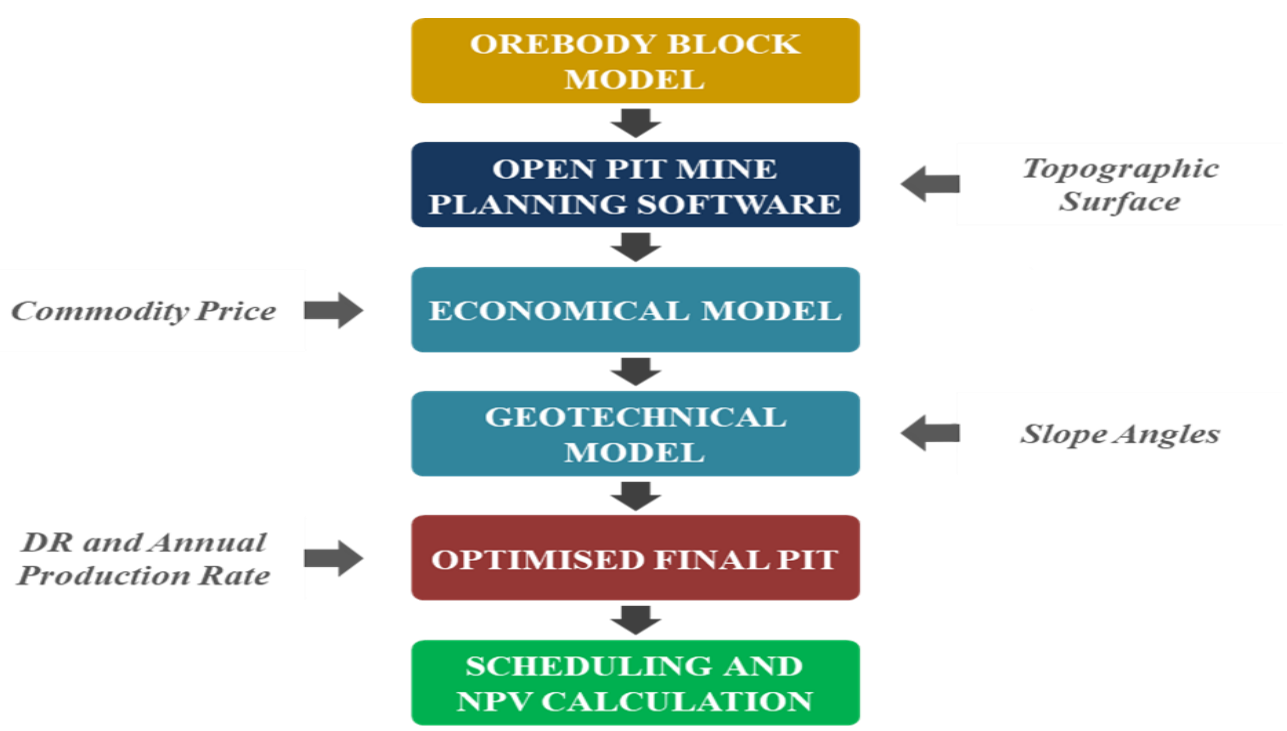

Figure 1 Flowchart schematically showing the steps of the methodology employed in this study.

\section{Results and discussion}

\subsection{Sensitivity Analysis in Terms of Price Variation}

After performing the steps described in the methodology, it was possible to obtain the results for the different price and discount rate scenarios. For the sensitivity analysis carried out solely in relation to the price, ore and waste tonnage values were calculated, as shown in Figure 4.

Analysing the results presented by the illustration in Figure 4, it can be observed that, for when the price is decreased, the overall tonnage of ore is smaller if compared to the baseline scenario of US $\$ 80 / t$. This behaviour was to be expected since once the commodity price decreases, blocks with lower $\mathrm{P}_{2} \mathrm{O}_{5}$ grades (although above the breakeven cut-off grade) tend to no longer be economically viable to be extracted, resulting in an overall decrease of the exploitable reserves, thereby shrinking the final pit limits.

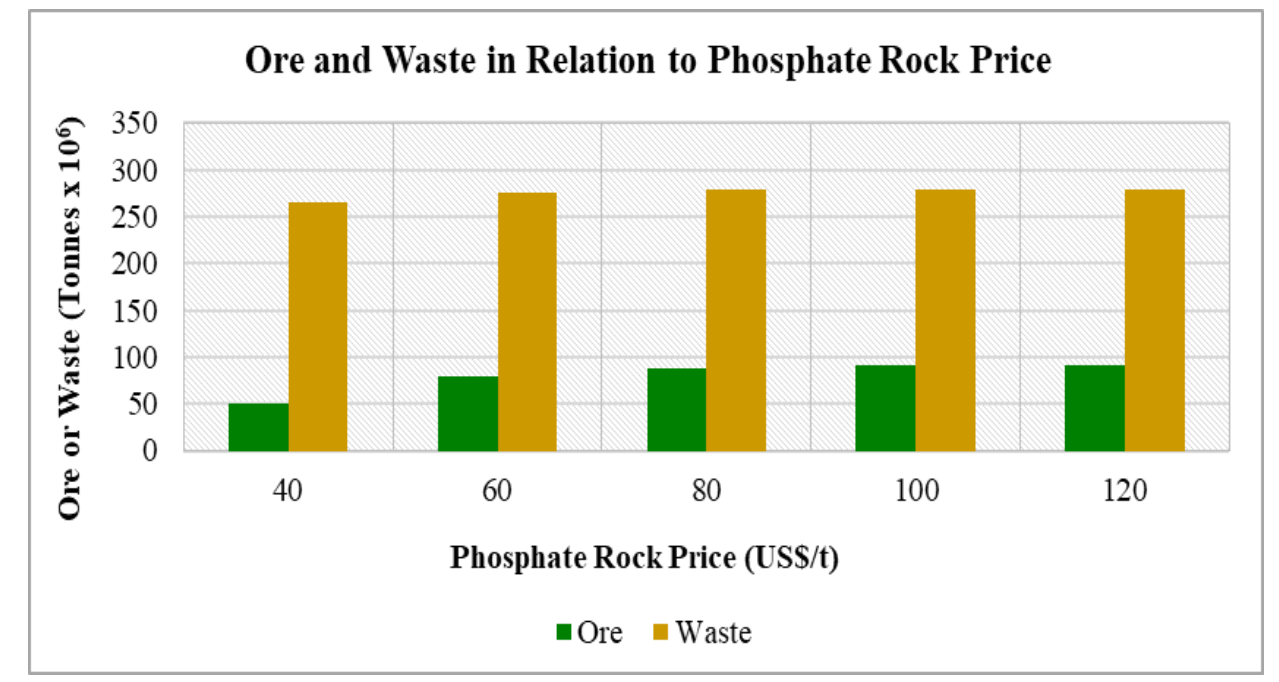

Figure 4 Comparative between all the price scenarios studied in terms of ore and waste tonnage. 
When comparing the baseline value of US\$ 80/t to the lowest price studied of US\$40/t, it was observed an approximately $44 \%$ reduction in the tonnage of ore, whilst for the highest price studied, considered to be US $\$ 120 / t$, an increase of only around 3\% was seen. The reason for this very modest increase in the tonnage of ore lies on the fact that, for this particular price, the pit limits were already close to those of the boundary conditions set at the beginning of the simulations, meaning that further pit expansions would not be possible, even if the price were increased to values above the ones studied in this paper.

Furthermore, according to the illustration in Figure 4, it is also possible to notice how the overall tonnage of waste changes little with each price increase or decrease. Comparing the baseline value of US\$ $80 / t$ to the worst price scenario of US $\$ 40 / t$, for example, it was observed a decrease of only around $4 \%$. And repeating the process, now for the highest price scenario of US\$120/t, the change observed in the tonnage of waste can be considered negligible. This shows that, as the final pit outline changed, the number of blocks labelled as "waste" either increased or decreased proportionally, thereby maintaining the overall tonnage of waste of the final pit somewhat constant throughout all the price scenarios evaluated.

The stripping ratio (SR) and the average grade of P205 of the final pit were also analysed. Figure 5 shows the behaviour of these two parameters in relation to the different price scenarios studied in this paper. The illustration in Figure 5 shows that, as the price decreases in value, the average grade of P205 increases. This behaviour is due to the fact that, with lower prices, certain blocks with marginal grade values yield negative profit, therefore being labelled as "waste" instead of "ore". In this case, the mining activities will focus only on the richest portion of the deposit, that is, where the grade values are high enough to compensate for the fall in the price, thereby increasing the overall average grade of the ore present in the final pit. On the other hand, as the price increases, blocks with lower grades, which were not economically feasible to be extracted before, become profitable, ultimately decreasing the overall average grade of P205 of the final pit.

The same logic can be applied to explain the behaviour of the curve that represents the stripping ratio values. Thus, for when the price is lower, a larger number of blocks with marginal grades of P205 (only slightly above the breakeven cutoff grade) have negative benefit values and must now be labelled as "waste", instead of "ore". This results in an increased number of blocks that are now labelled as "waste" compared to the ones that are labelled as "ore", consequently increasing the stripping ratio value. As the price increases, the precise opposite happens. Since the selling price is now higher, more blocks become economically feasible to be mined, ultimately reducing the stripping ratio until the final pit limits set by the boundary conditions are reached.

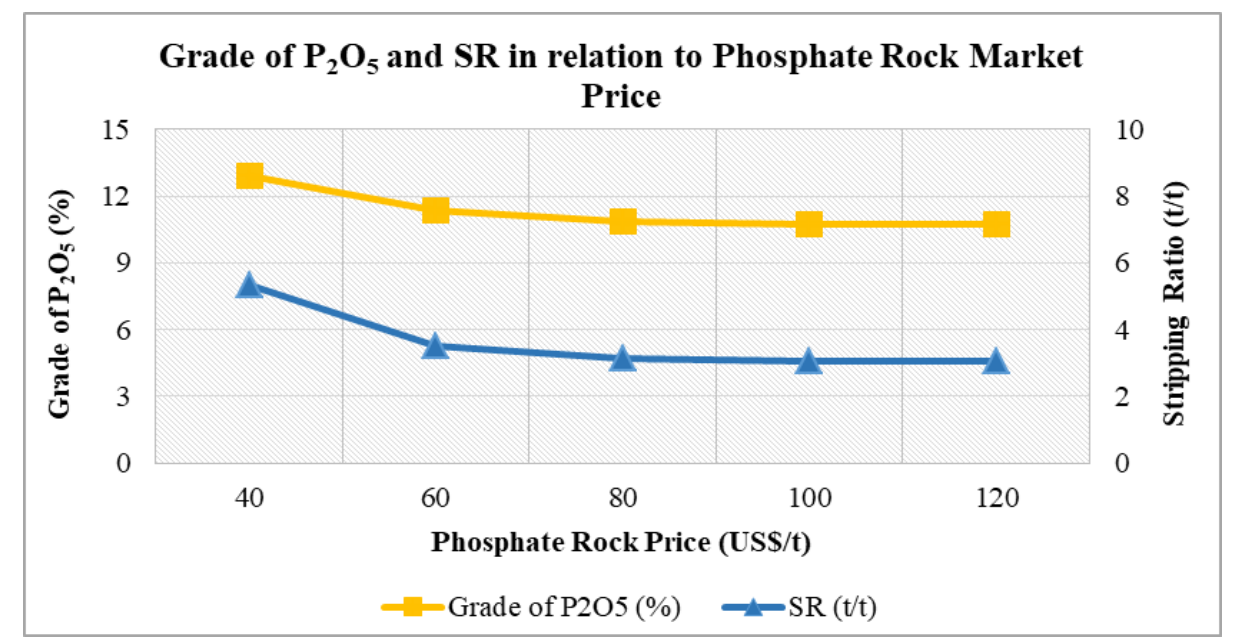

Figure 5 Comparative between the SR (t/t) and average grade of P205 (\%) for all the price scenarios evaluated in this study.

Lastly, as an approximation of the real production rate of the mineral deposit studied in this paper, a fixed annual production of 3.2 Mt of ore was considered and the life of mine was evaluated for each price scenario, as it can be seen in Figure 6. 
According to Figure 6, as the price decreases, so does the life of the mine. This was to be expected since, for lower prices, the mining is concentrated on the richer parts of the deposit, shrinking the final pit outline, and reducing the amount of material that is mined each year. Consequently, assuming a fixed production rate, as the final pit limits shrink, so does the life of mine. On the other hand, increases in the price tend to make blocks of lower grade become economically feasible to be mined, thereby expanding the final pit limits, and ultimately increasing the life of mine.

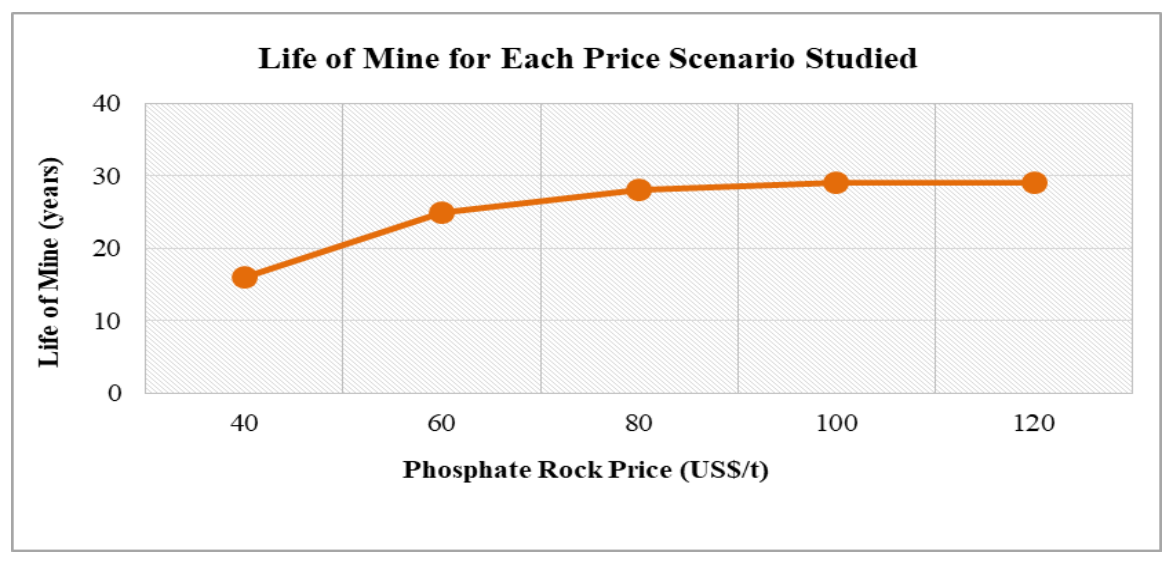

Figure 6 Life of the mine variation in relation to phosphate rock market price.

Lastly, no increase in the life of mine was observed going from the US\$100/t scenario to the US\$120/t scenario. This can be explained by the boundary conditions set with respect to physical constraints of the final pit limits, showing that, even if the price were to be increased further than US\$120/t, no significant changes would occur in the life of mine, as it was the case with the tonnage of ore as well.

\subsection{Sensitivity Analysis in Terms of Price and Discount Rate Variation}

The analysis of the effects of the discount rate was carried out solely with regard to the economic criterion, represented in this case by the NPV of the yearly cash flows of the mining business. Figure 7 shows the effects of the variation of the discount rate (DR) on the NPV for each price scenario evaluated in this paper.

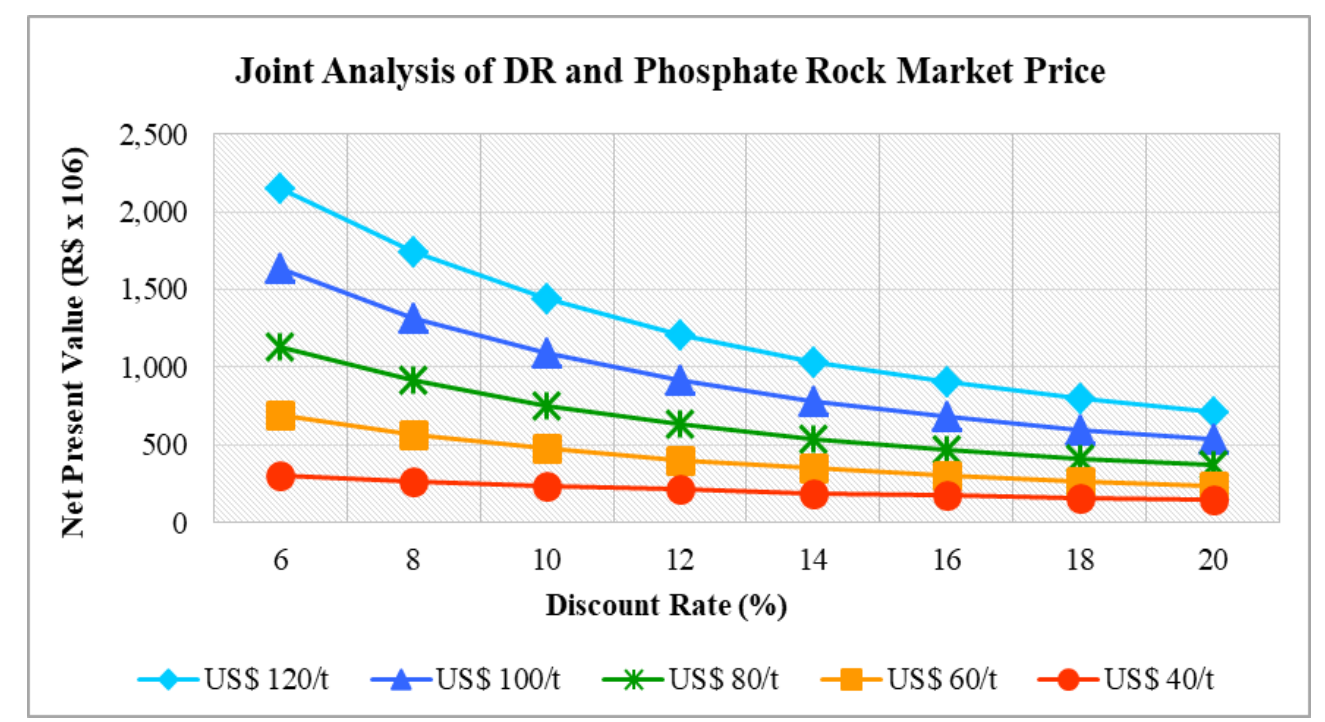

Figure 7 Comparative between all the price and discount rate scenarios.

According to Figure 7, when the commodity price is increased, the NPV also increases, regardless of the discount rate chosen. For the lowest price evaluated of US\$ 40/t, the NPV values were, on average, $66 \%$ lower than the baseline 
scenario of US\$ 80/t. On the other end of the spectrum, for the highest price assessed of US\$120/t, when compared to the baseline scenario, on average, an increase of approximately $92 \%$ in the NPV was observed. These numbers serve to demonstrate how changes in the price can substantially affect the profitability of the mining business.

Looking again at the illustration in Figure 7, now only in relation to the discount rate, there is a pattern that repeats itself throughout all the price scenarios evaluated. According to the illustration, it is possible to notice that, for smaller discount rate values, the NPV of the mining business is substantially greater than those of higher discount rates. The explanation to this lies on the fact that smaller discount rate values suggest a less uncertain scenario, where the yearly cash flows of the upcoming years are similar in terms of certainty to the one obtained at current time. In other words, a lower discount rate means that there is less uncertainty around the realisation of future cash flows. Conversely, higher discount rates reflect an unpredictable scenario, where the projections of future cash flows are volatile, which in turn makes it necessary to "penalise", so to speak, them in order to obtain the NPV of the mining undertaking.

In order to illustrate the effects of the variation of the discount rate in terms of the NPV, a reference value of $6 \%$ was adopted. This particular scenario is the one which is most favourable in terms of the profitability of the mining business since it suggests less uncertainty around future scenarios and was chosen solely for the purposes of demonstrating the extent of the changes in the NPV when the discount rate is altered.

Comparing the value of $12 \%$ with the reference value (6\%), the NPV decreased, on average, about $41 \%$, considering all the price scenarios evaluated in this paper. Furthermore, now comparing the worst case where the discount rate is $20 \%$, the NPV was, on average, $64 \%$ lower than of the reference value of $6 \%$.

Such variations serve to highlight how critical changes in the discount rate can be when the overall value of a business is obtained through the DCF method. It is also worth mentioning that choosing a smaller discount rate could potentially lead to an overestimation of the real value of the business, whilst choosing an unnecessarily high discount rate could undervalue the mining enterprise. Table I shows the percentage with which the NPV changed, in relation to the reference scenario of $6 \%$, as the discount rate was varied for every price scenario studied.

Table 1 Also shows that, for the lowest price evaluated of US\$ 40/t, the NPV variation in relation the discount rate is relatively smaller if compared to the other price scenarios.

Table 1 NPV variation in relation to the discount rate for each price scenario.

\begin{tabular}{|l|l|l|l|l|l|}
\hline \multicolumn{2}{|l}{ NPV VARIATION IN RELATION TO THE DISCOUNT RATE } \\
\hline Discount Rate (\%) & US\$40 & US\$ 60 & US\$ 80 & US\$ 100 & US\$ 120 \\
\hline 6 & $0 \%$ & $0 \%$ & $0 \%$ & $0 \%$ & $0 \%$ \\
\hline 8 & $-12 \%$ & $-18 \%$ & $-19 \%$ & $-19 \%$ & $-19 \%$ \\
\hline 10 & $-22 \%$ & $-31 \%$ & $-34 \%$ & $-34 \%$ & $-33 \%$ \\
\hline 12 & $-30 \%$ & $-42 \%$ & $-44 \%$ & $-44 \%$ & $-44 \%$ \\
\hline 14 & $-37 \%$ & $-50 \%$ & $-52 \%$ & $-52 \%$ & $-52 \%$ \\
\hline 16 & $-43 \%$ & $-56 \%$ & $-59 \%$ & $-58 \%$ & $-58 \%$ \\
\hline 18 & $-48 \%$ & $-61 \%$ & $-64 \%$ & $-63 \%$ & $-63 \%$ \\
\hline 20 & $-53 \%$ & $-66 \%$ & $-68 \%$ & $-67 \%$ & $-67 \%$ \\
\hline
\end{tabular}

A methodology that has been developed and applied in the mining industry since 1985 as an alternative to the traditional DCF methods is the Real Options Theory (ROT). In this methodology, the price of a certain mineral commodity, as all other variables, is not treated as fixed throughout the mining planning process. Instead, each variable will carry its own level of uncertainty which, in this case, will be represented by the volatility associated with each of them. In this way, ROT brings a more realistic approach to the planning process of an open pit mine, considering uncertainties in a way that is closer to real-world scenarios. 


\section{Conclusion}

As it was shown in this paper, long-term open pit mining planning deals with a great number of variables that not only are subject to changes over time, but also can influence the profitability and longevity of the mining business in a significant manner. Two of these variables, such as the commodity market price and the discount rate, have a substantial impact in the mining profitability. Increases in the market price, for instance, yielded a higher NPV and life of mine values. On the other hand, it was noted that increases in the discount rate can significantly alter the NPV, drastically reducing the value of the mining undertaking.

Furthermore, it was also noted that increasing the price from US\$100/t to US\$120/t resulted in little change in the tonnage of ore, tonnage of waste and, consequently, in the life of mine. This could be explained by the boundary conditions set for the simulations, meaning that further increases in the price above those studied in this paper would not result in further pit expansions.

It is also worth mentioning that, in this paper, only the commodity market price was changed in the profit function, with all other variables, such as operation costs, production schedule and geologic attributes remaining unchanged, which in reality is simply not true. Ultimately, the underlying goal of this work was to draw awareness to the importance of thinking of newer and perhaps more realistic approaches, such as ROT, in order to mitigate some of the limitations of the current methodology practised in the mining industry.

Lastly, this paper intended to help highlight how the traditional methodology employed in long-term open pit mine planning can sometimes lead to the overvaluation, or undervaluation, of the mining business, which in turn can lead to misguided investments decisions.

\section{Compliance with ethical standards}

\section{Acknowledgments}

The authors are grateful for the availability of the laboratories and software used at the Federal Center for Technology Education of Minas Gerais - CEFET-MG. And for the support of CAPES.

\section{Disclosure of conflict of interest}

There are no conflicts of interest.

\section{References}

[1] Relatório Anual de Atividades. jul/16-mai/17, IBRAM, agosto de 2017.

[2] Samis M. Valuing a multi-zone mine as a real asset portfolio - a modern asset pricing (real options) approach. In: 5TH Annual International Conference on Real Options. Theory Meets Practice, Los Angeles, California, United States. 2001.

[3] Dessureault S, Kazakidis VN, Mayer Z. Flexibility valuation in operating mine decisions using real options pricing. Int. J. Risk Assessment and Management. 2007; 7(5): 656 - 674.

[4] Dehghani H, Ataee-Pour M. Determination of the effect of economic uncertainties on mining project evaluation using real option valuation. Int. J. Mining and Mineral Engineering. 2013; 4(4): 265-277.

[5] Tourinho OAF. The Valuation of Reserves of Natural Resources: An Option Pricing Approach [PhD thesis]. United States of America: University of California. 1979.

[6] Palm SK, Pearson ND, Read JA. Option pricing: a new approach to mine valuation. In: Anderson FJ, Ed. Selected Readings in Mineral Economics. Ontario, Canada: Pergamon; 1986; 179-192.

[7] Dowd P. Risk assessment in reserve estimation and open-pit planning. Trans. The Institution of Mining and Metallurgy. 1994; 103: 148-154. 
[8] Dimitrakopoulos R, Farrelly CT, Godoy M. Moving forward from traditional optimization: grade uncertainty and risk effects in open-pit design. Transactions of the Institutions of Mining and Metallurgy: Section. 2002; 111(1): 82-88.

[9] Mardones JL. Option valuation of real assets. Resources Policy. 1993; 19(1): 51-65.

[10] Espinoza D, Goycoolea M, Moreno E, Muñoz G, Queyranne M. Open pit mine scheduling under uncertainty: a robust approach. In 36th APCOM - Applications of Computers and Operations Research in the Mineral Industry: Proceedings. Porto Alegre: Fundação Luiz Englert. 2013.

[11] Dimitrakopoulos R, Ramazan S. Uncertainty-based production scheduling in open pit mining. Society For Mining, Metallurgy, And Exploration. 2004; 316: 106-112.

[12] Dimitrakopoulos R, Martinez L, Ramazan S. A maximum upside minimum downside approach to the traditional optimization of open pit mine design. Journal of Mining Science. 2007; 43(1): 73-82.

[13] Abdel Sabour SA, Dimitrakopoulos RG, Kumral M. Mine design selection under uncertainty. Mining Technology. 2008; 117: 53 -.64.

[14] Meagher C, Abdel Sabour SA, Dimitrakopoulos R. Pushback design of open pit mines under geological and market uncertainties. In: Advances In Orebody Modelling and Strategic Mine Planning I, Spectrum Series. $2009 ; 17$.

[15] Marcotte D, Caron J. Ultimate open pit stochastic optimization. Computers \& Geosciences. 2013; 51: $238-246$.

[16] Asad MWA, Dimitrakopoulos R. Implementing a parametric maximum flow algorithm for optimal open pit mine design under uncertain supply and demand. Journal of the Operational Research Society. 2013; 64: $185-197$.

[17] Samis M, Davis GA, Laughton D, Poulin R. Valuing uncertain asset cash flows when there are no options: a real options approach. Resources Policy. 2006; 30: 285-298.

[18] Smith LD. Discount rates and risk assessment in mineral project evaluations. CIM Bulletin. 1995; 88 (989): 3443.

[19] Moyen N, Slade M, Uppal R. Valuing risk and flexibility. Resources Policy. 1996; 22(I/2): 63-74.

[20] Drieza JA, Kicki J, Saluga P. Real options in mine project budgeting - polish mining industry example. In: Third International Conference on Computer Simulation In Risk Analysis and Hazard Mitigation. Risk analysis III editor, C.A. Brebbia; organised by Wessex Institute of Technology. 2002; 27-36.

[21] Lerchs H, Grossmann IF. Optimum design of open pits mines. Transactions Canadian Mining and Metallurgical Bulletin. 1965; 58(633): 47-54. 